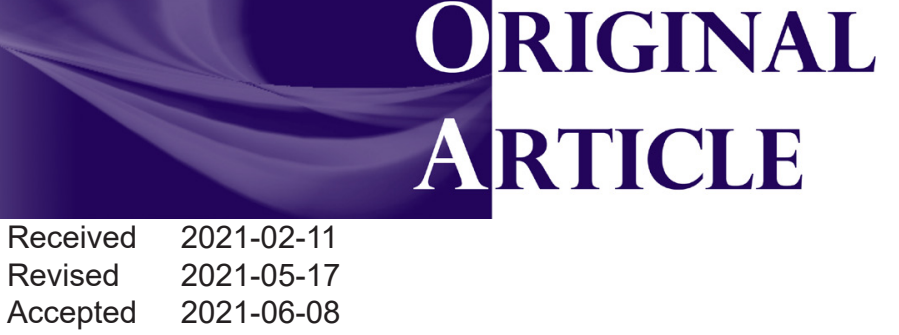

GMJ.2021;10:e2146

Www.gmj.ir

Revised 2021-05-17

Accepted 2021-06-08

\title{
Effects of Dexmedetomidine On the Postoperative Shivering, Nausea, and Vomiting Among Opium User Patients Undergoing Elective Supratentorial Brain Tumor Surgery: A Randomized, Placebo, Controlled Clinical trials
}

Mona Rajabi ${ }^{1,2}$, Davood $\mathrm{Ommi}^{3}$, Alireza $Z_{a l i}{ }^{4}$, Noor Mohammad Arefian ${ }^{5 凶}$

\footnotetext{
${ }^{1}$ Anesthesiology Research Center, Shahid Beheshti University of Medical Sciences, Tehran, Iran

${ }^{2}$ Noncommunicable Diseases Research Center, Fasa University of Medical Sciences, Fasa, Iran

${ }^{3}$ Functional Neurosurgery Research Center, Shahid Beheshti Medical University, Tehran, Iran

${ }^{4}$ Functional Neurosurgery Research Center, Shohada Tajrish Neurosurgical Center of Excellence, Shahid Beheshti University of

Medical Sciences, Tehran, Iran

${ }^{5}$ Anesthesiology Department, School of Medicine, Shahid Beheshti University of Medical Sciences, Tehran, Iran
}

\begin{abstract}
Background: Postoperative nausea and vomiting (PONV), and shivering are common general anesthesia complications. Hence, this study evaluates the effect of dexmedetomidine, given as a premedication, on PONV and shivering in patients with opium use who underwent elective supratentorial brain tumor surgeries. Materials and Methods: In a randomized clinical trial, 100 opium user patients who were candidates for elective supra-tentorial brain tumor surgery under general anesthesia were studied in two groups of 50 patients. The intervention group received dexmedetomidine (within 10 and 30 minutes infusion) before the anesthesia induction. Group placebo that received normal saline as a group. PONV and shivering rates were compared between the two groups. Results: Both groups did not differ in hemodynamic parameters during operation, including pulse rate, systolic and diastolic blood pressure, and anesthesia duration. In the dexmedetomidine group, patients suffered less from PONV and shivering rather than controls, and these differences were both significant ( $\mathrm{P}=0.001$ and $\mathrm{P}=0.027$, respectively). Discussion: Dexmedetomidine administration before major surgeries might reduce post-operative nausea and vomiting and the occurrence of shivering, particularly in opium-addicted patients. [GMJ.2021;10:e2146] DOI:10.31661/gmj.v10i0.2146
\end{abstract}

Keywords: Dexmedetomidine; General Anesthesia; Nausea; Vomiting; Shivering 


\section{Introduction}

G eneral anesthesia is used in many surgeries, followed by several complications, including nausea, vomiting, shivering, and hemodynamic instability [1]. Shivering is a protective mechanism against a decrease in central body temperature, which begins with the perception of low temperature by the preoptic nucleus of the hypothalamus [2]. Shivering occurs after regional and general anesthesia, although the incidence is higher after general anesthesia, with an incidence rate of $50-60 \%$ in the normal population [3].

The presence of shivering can upset the balance between demand and oxygen supply, which increases the oxygen demand up to six times more than routine conditions causing hypoxia, lactic acidosis, and hypercarbia [4]. Postoperative nausea and vomiting (PONV) and shivering are common general anesthesia complications [5]. PONV may lead to more serious difficulties such as aspiration and suture dehiscence [6]. It causes electrolyte disturbances, worsening bleeding, prolonged recovery, and hospitalization in patients [7].

Some studies have shown several drugs effective in decreasing PONV, but there are not any proven ones yet. Karen et al. investigated the comparative efficacy and safety of ondansetron, droperidol, and metoclopramide to prevent PONV and finally reported ondansetron and droperidol as more effective drugs than metoclopramide in reducing postoperative vomiting [8].

The effectiveness of dexmedetomidine administration during or before surgery on diminishing PONV has been argued in some studies [9, 10]. Dexmedetomidine is a highly a2-adrenoreceptor agonist that binds to the transmembrane G-protein receptor and has no effect on the gamma-aminobutyric acid system [11, 12]. It has sedative, analgesic, sympatholytic, and amnestic properties [13] that increase the shivering threshold in patients [14].

Furthermore, patients with opium use are more prone to postoperative complications and exhibit tolerance to many drugs; therefore, anesthesia management in this group is a significant concern for anesthesiologists. Thus, the present study was conducted to evaluate the effect of dexmedetomidine, given as a premedication, on PONV and shivering among patients with opium use who underwent elective supratentorial brain tumor surgeries.

\section{Materials and Methods}

\section{Design and Population}

The present study was a randomized placebo-controlled clinical trial that included 180 opium-addicted patients (18-65 years) who candidates for elective supratentorial brain tumor surgeries that visited in tertiary healthcare hospital affiliated to Shahid Beheshti University of Medical Sciences, Tehran, Iran. The study included all the patients who used at least 4 grams per day of opium (natural or semisynthetic alkaloids) as the oral or inhalational route for more than six months. All enrolled patients met the study inclusion criteria such as class 1 and 2 American Society of Anesthesiologists (ASA), surgery duration less than 4 hours, systolic blood pressure during 24 hours before surgery between 140 to 90 $\mathrm{mmHg}$, a saturation of oxygen more than $90 \%$ in room air, and normal body temperature (ranged from $36.8{ }^{\circ} \mathrm{C}$ to $37.2{ }^{\circ} \mathrm{C}$ ). Patients with a history of coronary artery disease or arrhythmia, fractures or multiple trauma, gastrointestinal disease, PONV or pre-operation shivering, opioid withdrawal symptoms before surgery, antiemetic drugs consumption, and history of motion sickness were excluded from the study.

\section{Sample Size Calculation}

Regarding the previous studies $[1,15,16]$ in this field, while taking into account the assumptions: the power of $80 \%$, the error of $5 \%$, the effect size of about $40 \%$, or the risk ratio of about three percent in the two groups, and the ratio of one to one in two groups were all measured using the following formula:

$n=\frac{2 \bar{p}(1-\bar{p})\left(z_{1-\alpha / 2}+z_{1-\beta}\right)^{2}}{(\delta)^{2}}$

Considering a $5 \%$ drop in total amount obtained from the computations, a total of at least 50 patients in each group are needed. 


\section{Randomization}

We randomly assigned patients with a 1:1 aspect ratio to receive either dexmedetomidine or placebo, employing a computer-based program following random number generator protocol. The patients were categorized into two groups of 50 participants. The participants were classified via an online calculator at www.calculator.net, and based on the calculator's output, each patient was randomly assigned a number. The control group includes number 1 to number 50, and the intervention group contains number 51 to number 100 . Further, both groups were the same regarding age and gender frequency distribution.

\section{Intervention}

Dexmedetomidine and placebo were both of the same appearance and color and had similar packages. Moreover, they both received a code, either A or B, by a person other than the researcher. Both groups received midazolam $(0.03 \mathrm{mg} / \mathrm{kg})$, fentanyl (2-3 mcg $/ \mathrm{kg})$, propofol $(1.5-2 \mathrm{mg} / \mathrm{kg})$, and cisatracurium $(0.2 \mathrm{mg} / \mathrm{kg})$ for anesthesia induction. Thirty minutes before the anesthesia induction, the intervention group received an intravenous (IV) infusion of dexmedetomidine $(1 \mathrm{mcg} / \mathrm{kg} / \mathrm{min})$ within 10 and 30 minutes prior to the anesthesia induction; the control group received an infusion of normal saline within 10 minutes. Thereby using O2/air as 2/1 liter/min, maintenance of anesthesia was provided, and the value of cerebral state index (CSI) was kept between 40 to 60 via infusing propofol at a dosage of $100-300 \mu \mathrm{g} / \mathrm{kg} / \mathrm{min}$. Also, systolic and diastolic blood pressure, heart rate, saturation of oxygen, and cardiac rhythm were monitored and recorded. Following obtaining the required criteria for reversal of neuromuscular blockade, endotracheal tubes were extubated from the patients after the surgery. Then they were transferred to the post-anesthesia care unit with hemodynamic and ventilation monitoring.

\section{Primary Outcomes}

Upon the patient's arrival in the recovery room, all the information was recorded from minute 1 to minute 150 . In order to assess research variables such as nausea and vomiting, the observation method was applied by the anesthesiologist and a trained nurse during post-operative recovery. Shivering incidence, muscular activity in any muscle groups, and patients' recovery time were recorded by a nurse who was not informed of the patients' opium user and premedication. The bedside shivering assessment scale (BSAS) was applied to evaluate shivering, where shivering scores were 2 and 3.

\section{Ethical Consideration}

The present study was registered at the Iranian Registry of Clinical Trials with a registration number of IRCT20201122049464N1. Likewise, it was approved by the institutional review board of Shahid Beheshti University of Medical Sciences and won the approval of the Ethical Committee (approval code: R.SBMU. MSP.REC.1398.126). Also, written informed consent was obtained from all the participants in the study.

\section{Statistical Analyses}

The collected data was placed into the statistical package for social sciences SPSS (version 21, IBM. Corporation, Armonk, NY, USA). Descriptive statistics, including mean, standard deviation(SD) for quantitative variables, and number and percent for qualitative variables, were used. Independent sample t-test was used to compare the mean of parameters in each of the two groups.

The Chi-square test was also employed to compare the qualitative variables and qualities for the two groups. Also, analysis of variance (ANOVA) with interaction was applied to perform statistical data analysis. P-values of less than 0.05 were considered statistically significant.

\section{Results}

The flowchart of the study is presented in Figure-1. The participants' mean age was $42.14 \pm 13.65$ and $41.70 \pm 13.22$ years in the intervention and control group, respectively $(\mathrm{P}=$ 0.76). Table-1 shows baseline characteristics and laboratory findings of the two groups. There were not any significant differences between the two groups comparing baseline data 


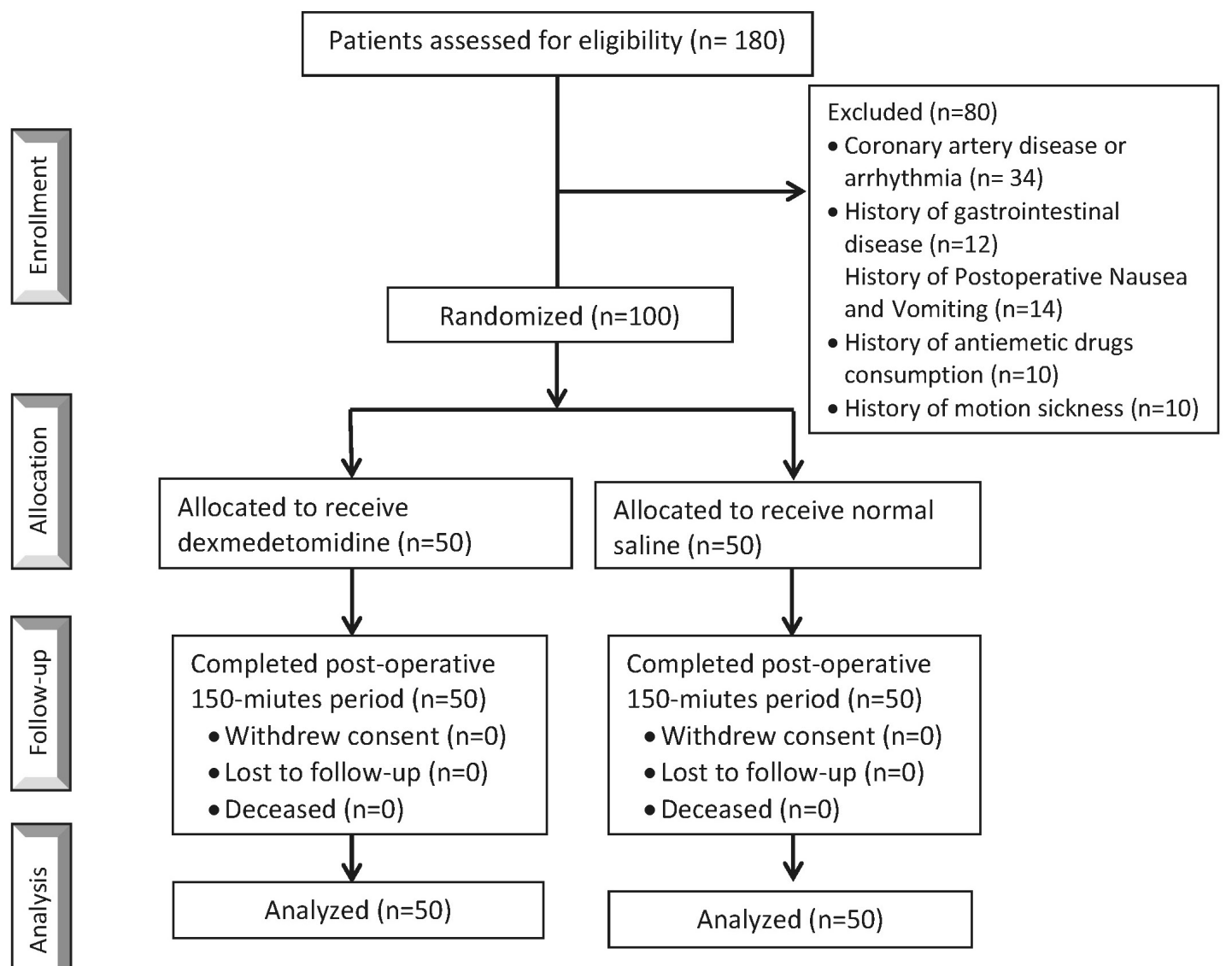

Figure 1. CONSORT flow diagram of this trial.

Table 1. Baseline Characteristics and Laboratory Findings of Two Groups.

\begin{tabular}{lccc}
\hline Variables & $\begin{array}{c}\text { Saline group } \\
(\mathbf{n}=\mathbf{5 0})\end{array}$ & $\begin{array}{c}\text { Dexmedetomidine group } \\
(\mathbf{n = 5 0 )}\end{array}$ & P-value \\
\hline Age (year), mean \pm SD & $41.70 \pm 13.22$ & $42.14 \pm 13.65$ & 0.76 \\
Weight $(\mathbf{k g})$, mean \pm SD & $69.32 \pm 11.3$ & $70.58 \pm 10.4$ & 0.69 \\
Gender, number & & & \\
$\quad$ Male & 33 & 32 & 0.83 \\
$\quad$ Female & 17 & 18 & \\
Laboratory data & & & \\
$\quad$ Platelet, mean \pm SD & $301.46 \pm 63.8$ & $298.52 \pm 65.3$ & 0.6 \\
$\quad$ Red blood cells $(\mathrm{m})$ & 5.5 & 5.6 & 0.38 \\
Hemoglobin, mean \pm SD & $14.5 \pm 1.19$ & $14.88 \pm 1.5$ & 0.18 \\
PT (second), mean \pm SD & $11.96 \pm 1.12$ & $11.86 \pm 1.16$ & 0.47 \\
PTT (second), mean \pm SD & $33 \pm 2.7$ & $33.16 \pm 3.11$ & 0.85 \\
$\quad$ INR, mean \pm SD & $1.06 \pm 0.07$ & $1.09 \pm 0.07$ & 0.05 \\
\hline
\end{tabular}

Kg: Kilogram; M: Million; PT: Prothrombin Time; PTT: Partial Thromboplasine Time; INR: Intenational Unit 
and laboratory results.

\section{Clinical Efficacy Endpoints}

A hemodynamic conditions during the operation were recorded and compared between the two groups. According to Table-2, both groups have no difference in the term of hemodynamic parameters during operation, including pulse rate, systolic and diastolic blood pressure, and anesthesia duration time.

In general, the occurrence of post-operation shivering in patients who had received dexmedetomidine was significantly less than in the control group. Figure-2 demonstrates the number of persons who experienced shivering at different times after the operation. Over time, the number of post-operation shivering episodes in both groups decreased after re- ceiving medications, but in the dexmedetomidine group, post-operation shivering touched zero lines significantly faster than the saline group $(\mathrm{P}=0.027)$.

Both groups meaningfully differed in terms of the number of patients who suffered from PONV. From the commencement of post-anesthesia recovery until minute 30 , remarkably, fewer patients with PONV were observed in the dexmedetomidine group than the saline group $(\mathrm{P}=0.001)$. Since minute 40 , both groups were the same in this regard (Figure-3).

\section{Discussion}

The present study showed that perioperative infusion of dexmedetomidine reduced shiv-

Table 2. Comparison of Hemodynamic Parameters During Operation Between Two Groups.

\begin{tabular}{lccc}
\hline Parameters & $\begin{array}{c}\text { Saline group } \\
(\mathbf{n}=\mathbf{5 0})\end{array}$ & $\begin{array}{c}\text { Dexmedetomidine } \\
\text { group }(\mathbf{n}=\mathbf{5 0})\end{array}$ & P-value \\
\hline Heart rate & 77 & 73 & 0.65 \\
SBP $(\mathbf{m m H g})$, mean \pm SD & $124.42 \pm 17.78$ & $127.42 \pm 7.5$ & 0.18 \\
DBP $(\mathbf{m m H g})$, mean \pm SD & $84.46 \pm 4.2$ & $85.18 \pm 5.08$ & 0.45 \\
Duration of anesthesia (minute), mean \pm SD & $161.6 \pm 23.15$ & $157 \pm 21.21$ & 0.17 \\
\hline
\end{tabular}

SBP: Systolic Blood Pressure; DBP: Diastolic Blood Pressure

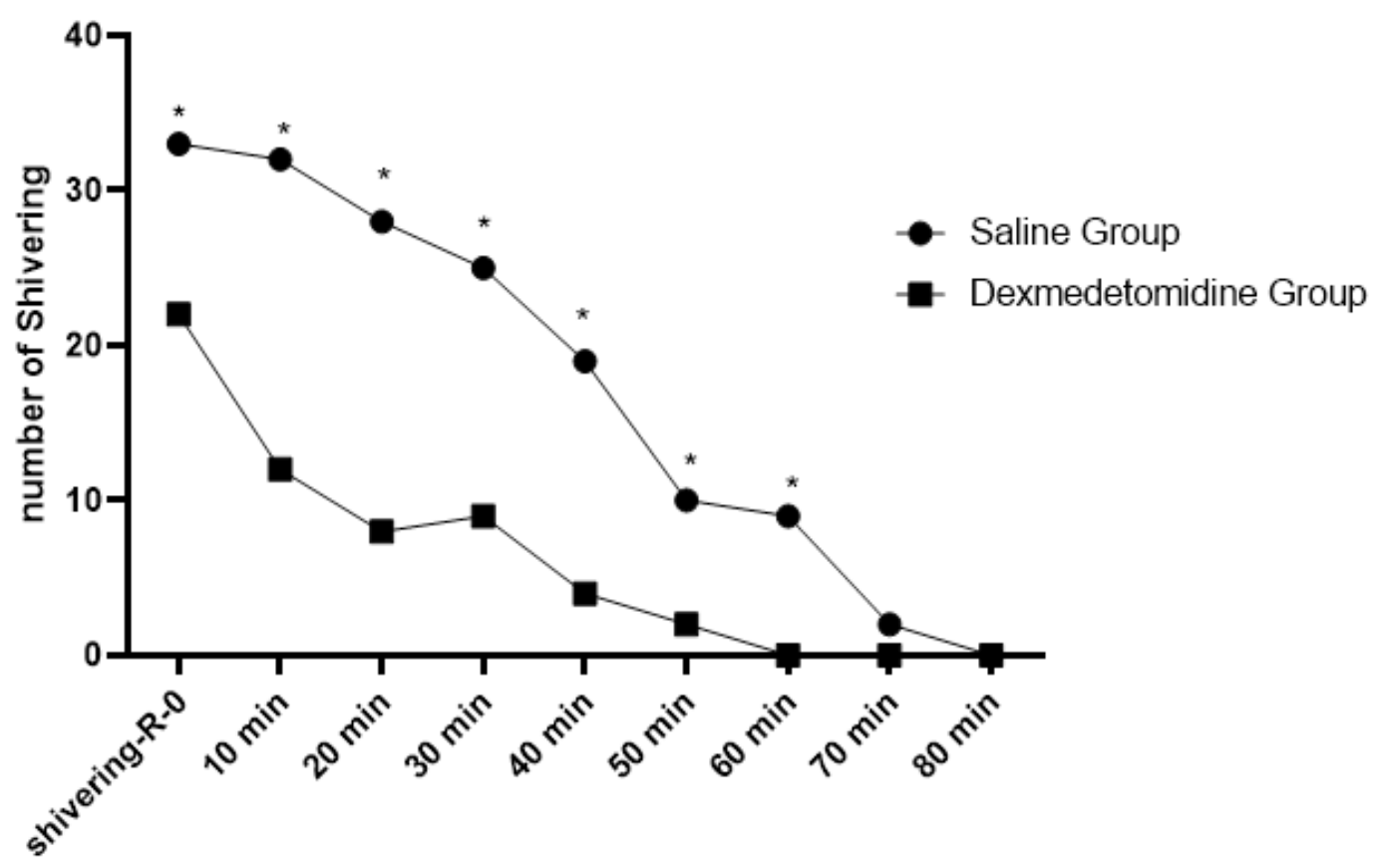

Figure 2. Number of shivering occurrences over time in two groups. ${ }^{*} P<0.05$ vs. saline group. 


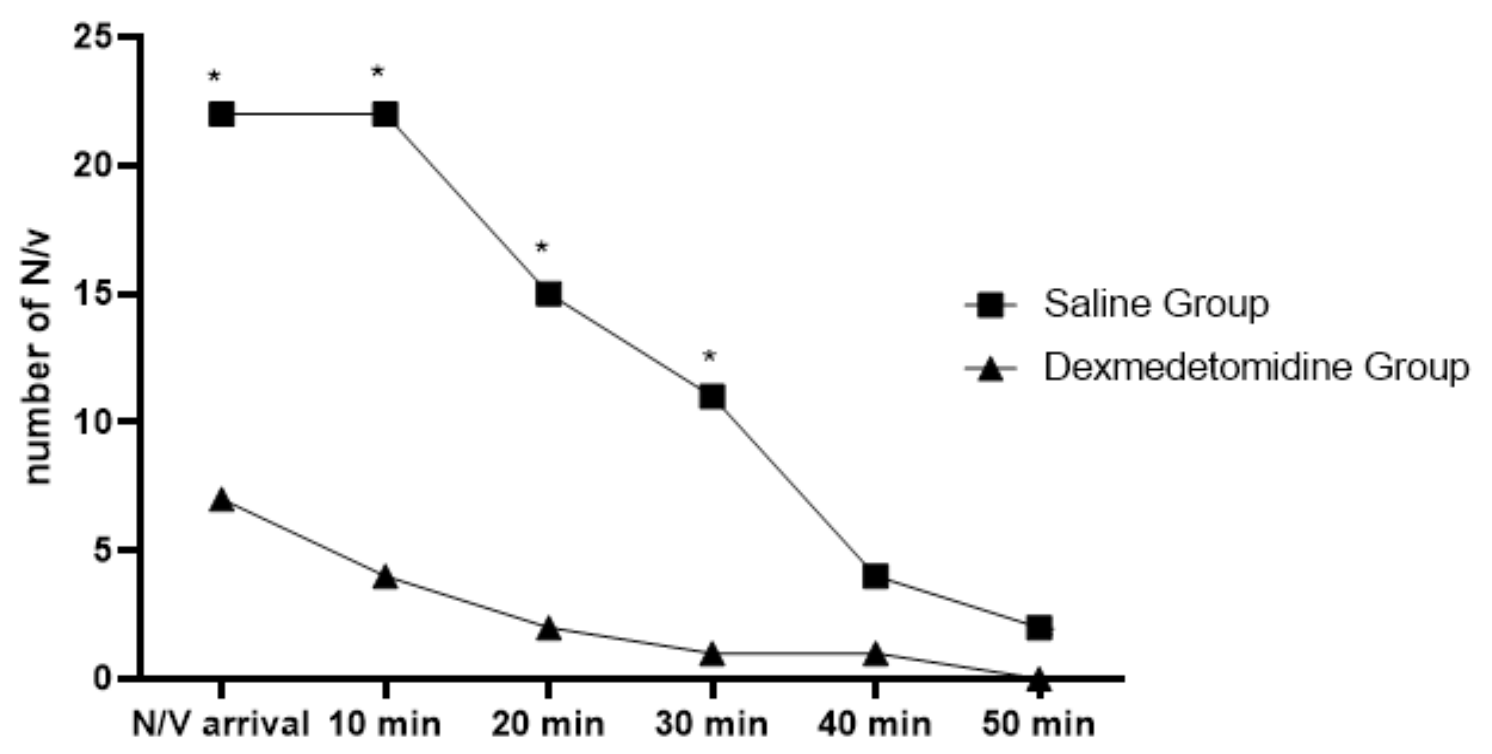

Figure 3. Number of PONV occurrence over time in two groups. ${ }^{*} P<0.05$ vs. saline group.

ering and PONV in opioid-addicted patients. It could be noticed that dexmedetomidine administration before operation decreases the frequency of PONV and the duration of this disturbing post-operation complication in patients who tolerate major surgeries.

Many risk factors are contributed to post-anesthetic shivering, but the major ones are intraoperative hypothermia [17]. An important role of dexmedetomidine is to prevent shivering as it affects patients' shivering threshold [14]. In the Bicer et al. study effect of postoperative administration of $1 \mu \mathrm{g} / \mathrm{kg}$ IV bolus dexmedetomidine $(0.5 \mathrm{mg} / \mathrm{kg} \mathrm{IV})$, meperidine, and placebo on the occurrence of shivering were compared. The study revealed that shivering was observed in $15 \%, 10 \%$, and $55 \%$ of patients in the dexmedetomidine, meperidine, and placebo groups, respectively [18]. Another study concluded that dexmedetomidine was better than a placebo but not different from other anti-shivering agents [19]. In addition, PONV is a common dissatisfaction among patients after general anesthesia [20]. Multifactorial risk factors, including anesthetic agent, anesthesia type, surgical technique, and patient characteristics, could cause post-anesthesia PONV [21]. Thus, anesthesiologists and surgeons endeavor to identify patients at increased risk of PONV to take the required preventive measures [22]. Recent- ly, aiming at ameliorating the PONV complication, multimodal approaches have been applied, among which the administration of combined antiemetic therapies, preoperative anxiolysis, adequate hydration, and local analgesic techniques are remarkable [23]. Further studies were set out to examine the effect of dexmedetomidine on PONV. For instance, Goksu et al. reported a meaningfully lower incidence of PONV in the dexmedetomidine group compared to the placebo group where dexmedetomidine was used as a sedation during functional endoscopic sinus surgery under local anesthesia [24]. A significant decrease in the PONV occurrence after laparoscopic gynecological surgeries was achieved via using dexmedetomidine along with other anesthetic agents [25]. One meta-analysis also proved that dexmedetomidine significantly reduced postoperative PONV [26].

Although many studies had been previously carried out investigating the effect of dexmedetomidine on postoperative PONV and shivering, the present survey indicates that perioperative infusion of dexmedetomidine can control PONV and shivering in opioid-addicted patients. This was the first study about dexmedetomidine's effects on recovery time after anesthesia among opioid users to the best of our knowledge. However, we were faced with some limitations; for example, it was not 
possible to include equal numbers of patients of both sexes, which resulted in male patients' dominance in number. Therefore, it seems that we cannot generalize our results to both sexes. Another limitation was that we did not have any laboratory data about the patient's opioid blood level or opioid level in their urine drug screen results. Being committed to preserving patients' rights and trying not to cause any discomfort to them by asking them for any substance abuse tests, we had to rely on the history provided by the patients about their addiction.

\section{Conclusion}

Finally, we concluded that dexmedetomidine administration before major surgeries might reduce PONV and the occurrence of shiver- ing, particularly in opium-addicted patients. Additionally, it could be administered as a safe drug to lower recovery time after general anesthesia and duration of postoperative complications such as nausea and vomiting.

\section{Acknowledgments}

We would like to thank all the patients who participated in this study. The authors received no financial support (grant number:18420) for the research, authorship, and/or publication of this article.

\section{Conflict of Interest}

The authors declared no conflict of interest in the study.

\section{References}

1. Moghaddam MJ, Ommi D, Mirkheshti A, Dabbagh A, Memary E, Sadeghi A et al. Effects of clonidine premedication upon postoperative shivering and recovery time in patients with and without opium addiction after elective leg fracture surgeries. Anesth Pain Med. 2013;2(3):107.

2. Giesbrecht GG, Sessler DI, Mekjavic IB, Schroeder M, Bristow GK. Treatment of mild immersion hypothermia by direct body-to-body contact. J Appl Physiol1994;76(6):2373-9.

3. Powell RM, Buggy DJ. Ondansetron given before induction of anesthesia reduces shivering after general anesthesia. Anesth Analg. 2000;90(6):1423-7.

4. Mathews S, Al Mulla A, Varghese P, Radim K, Mumtaz S. Postanaesthetic shivering a new look at tramadol. Anaesthesia. 2002;57(4):387-403.

5. Stadler M, Bardiau F, Seidel L, Albert A, Boogaerts JG. Difference in risk factors for postoperative nausea and vomiting. Anesthesiology. 2003;98(1):46-52.

6. Cao X, White PF, Ma H. An update on the management of postoperative nausea and vomiting. J Anesth. 2017;31(4):617-26.

7. Lin CJ, Williams BA. Postoperative nausea and vomiting in ambulatory regional anesthesia. J Appl Physiol. 2011;49(4):13443.
8. Domino KB, Anderson EA, Polissar NL, Posner KL. Comparative efficacy and safety of ondansetron, droperidol, and metoclopramide for preventing postoperative nausea and vomiting: a meta-analysis. Anesth Analg. 1999;88(6):1370-9.

9. Jin S, Liang DD, Chen C, Zhang M, Wang J. Dexmedetomidine prevent postoperative nausea and vomiting on patients during general anesthesia: A PRISMA-compliant meta analysis of randomized controlled trials. Medicine (Baltimore). 2017;96(1):1-7.

10. Massad IM, Mohsen WA, Basha AS, AlZaben KR, Al-Mustafa MM, Alghanem SM. A balanced anesthesia with dexmedetomidine decreases postoperative nausea and vomiting after laparoscopic surgery. Saudi Med J. 2009;30(12):1537-41.

11. Keating GM, Hoy SM, Lyseng-Williamson KA. Dexmedetomidine: a guide to its use for sedation in the US. Clin. Drug Investig. 2012;32(8):561-7.

12. Salimi A, Sharifi G, Bahrani H, Mohajerani SA, Jafari A, Safari F et al. Dexmedetomidine could enhance surgical satisfaction in Trans-sphenoidal resection of pituitary adenoma. J Neurosurg Sci. 2017;61(1):46-52.

13. Bakan M, Umutoglu T, Topuz U, Uysal H, Bayram M, Kadioglu H et al. [Opioid-free total intravenous anesthesia with propofol, 
dexmedetomidine and lidocaine infusions for laparoscopic cholecystectomy: a prospective, randomized, double-blinded study]. Rev Bras Anestesiol. 2015;65(3):191-9.

14. Bajwa SJ, Gupta S, Kaur J, Singh A, Parmar $\mathrm{S}$. Reduction in the incidence of shivering with perioperative dexmedetomidine: A randomized prospective study. J Anaesthesiol Clin Pharmacol. 2012;28(1):86-91.

15. Moghadam MJ, Ommi D, Mirkheshti A, Shadnoush M, Dabbagh A. The effect of pretreatment with clonidine on propofol consumption in opium abuser and non-abuser patients undergoing elective leg surgery. $\mathrm{J}$ Res Med Sci. 2012;17(8):728.

16. Ommi D, Teymourian H, Zali A, Ashrafi F, Moghaddam MJ, Mirkheshti A. Effects of clonidine premedication on intraoperative blood loss in patients with and without opium addiction during elective femoral fracture surgeries. Anesth Pain Med. 2015;5(4):1-6.

17. Panzer O, Ghazanfari N, Sessler DI, Yucel Y, Greher M, Akca O et al. Shivering and shivering-like tremor during labor with and without epidural analgesia. Anesthesiology. 1999;90(6):1609-16.

18. Bicer C, Esmaoglu A, Akin A, Boyaci A. Dexmedetomidine and meperidine prevent postanaesthetic shivering. Eur J Anaesthesiol. 2006;23(2):149-53.

19. Liu ZX, Xu FY, Liang X, Zhou M, Wu L, $\mathrm{Wu}$ JR et al. Efficacy of dexmedetomidine on postoperative shivering: a metaanalysis of clinical trials. Can J Anaesth. 2015;62(7):816-29.

20. Gan TJ, Meyer T, Apfel CC, Chung F, Davis PJ, Eubanks S et al. Consensus guidelines for managing postoperative nausea and vomiting. Anesth Analg. 2003;97(1):62-71

21. Watcha MF, White PF. Postoperative nausea and vomiting. Its etiology, treatment, and prevention. Anesthesiology. 1992;77(1):16284.
22. Lee SJ, Lee SM, Kim SI, Ok SY, Kim SH, Park SY et al. The effect of aprepitant for the prevention of postoperative nausea and vomiting in patients undergoing gynecologic surgery with intravenous patient controlled analgesia using fentanyl: aprepitant plus ramosetron vs ramosetron alone. Korean J Anesthesiol. 2012;63(3):221-6.

23. Riley TJ, McKenzie R, Trantisira BR, Hamilton DL. Droperidol-ondansetron combination versus droperidol alone for postoperative control of emesis after total abdominal hysterectomy. J Clin Anesth. 1998;10(1):6-12.

24. Scuderi PE, James RL, Harris L, Mims GR, 3rd. Multimodal antiemetic management prevents early postoperative vomiting after outpatient laparoscopy. Anesth Analg. 2000;91(6):1408-14.

25. Goksu S, Arik H, Demiryurek S, Mumbuc $\mathrm{S}$, Oner U, Demiryurek AT. Effects of dexmedetomidine infusion in patients undergoing functional endoscopic sinus surgery under local anaesthesia. Eur J Anaesthesiol. 2008;25(1):22-8.

26. Massad IM, Mohsen WA, Basha AS, AlZaben KR, Al-Mustafa MM, Alghanem SM. A balanced anesthesia with dexmedetomidine decreases postoperative nausea and vomiting after laparoscopic surgery. Saudi Med J. 2009;30(12):1537-41.

27. Blaudszun G, Lysakowski C, Elia N, Tramer MR. Effect of perioperative systemic alpha 2 agonists on postoperative morphine consumption and pain intensity: systematic review and meta-analysis of randomized controlled trials. Anesthesiology. 2012;116(6):1312-22. 